\title{
Walter Benjamin pós-marxista: da desconstrução benjaminiana à filosofia da história do marxismo.
}

Francisco Ramos Neves ${ }^{1}$

\begin{abstract}
Resumo
0 presente ensaio aponta uma tese polêmica acerca das referências filosóficas de Walter Benjamin, que nega sua filiação ao pensamento marxista. Contrariando alguns comentadores apresentamos um Benjamin crítico do marxismo, sobretudo, no que diz respeito à sua concepção de filosofia da história. A análise desconstrutiva benjaminiana da razão instrumental envolve a tradição racionalista, submetida aos princípios do determinismo da causalidade histórica em um continuísmo. Nesta abordagem crítico-teórica o marxismo é identificado como parte desta tradição. Palavras-chaves: Benjamin - Teoria Crítica - filosofia da história - desconstrução
\end{abstract}

\begin{abstract}
This essay indicates a polemic thesis about the philosophical references of Walter Benjamin, that deny your affiliation with Marxist thought. Contradicting some commentators we present a Benjamin critic of Marxism, especially with respect to the your conception of philosophy of history. The deconstructive analysis benjaminiane of instrumental reason involves the rationalist tradition, submitted to the principles of the determinism of historical causation in continuity. In this critical approach-theoretic the Marxism is identified as part of this tradition.
\end{abstract}

Keywords: Benjamin - Critical Theory - Philosophy of history - deconstruction

Conhecemos a história de um autômato construído de tal modo que podia responder a cada lance de um jogador de xadrez com um contra lance, que lhe assegurava a vitória. Um fantoche vestido à turca, com um marguilé na boca, sentava-se diante de um tabuleiro, colocado numa grande mesa. Um sistema de espelhos criava a ilusão de que a mesa era totalmente visível, em todos os seus pormenores. Na realidade, um anão corcunda se escondia nela, um mestre no xadrez, que dirigia com cordéis a mão do fantoche. Podemos imaginar uma contrapartida filosófica desse mecanismo. $O$ fantoche chamado 'materialismo histórico' ganhará sempre. Ele pode enfrentar qualquer desafio, desde que tome a seu serviço a teologia. Hoje, ela é reconhecidamente pequena e feia e não ousa mostrar-se. ${ }^{2}$

\footnotetext{
${ }^{1}$ Professor assistente III de Filosofia - DFI-UERN - Doutorando em Filosofia - UFPE-UPPB - UFRN professor.ramos@hotmail.com.br

2 BENJAMIN, Walter. Teses Sobre o Conceito da História. in. __. Magia e Técnica, Arte e Política. 2.ed. São Paulo: Brasiliense, 1986. (Obras Escolhidas, v. 1) Tese 1, p. 222 (doravante denominaremos apenas "Teses...").
} 
Como metáfora a primeira das 'teses sobre o Conceito da História' abre os manuscritos benjaminianos sobre a história apontando com uma linguagem alegórica a relação do materialismo marxista com a teologia, no sentido da determinação racionalista da história.

A teologia e o racionalismo teleológico marxista se unificam na ideia de determinação necessária e escatológica da história. Segundo Karl Löwith, a filosofia moderna da história, em seus principais expoentes, desde a mística hebraico-cristã, passando por Santo Agostinho, Joaquim de Fiore, Bossuet, Vico, Condorcet, Comte até Karl Marx, concebe a história em uma "totalidade" fechada do tempo histórico da humanidade, manifesto no plano da "salvação", história da salvação. Definindo um absoluto (Deus ou uma razão instrumental) como o "eskhaton" em uma teleologia do idêntico (a mesmidade) na história, que se originou de uma fé em um fim último. ${ }^{3}$

A aceitação incondicional da determinação absoluta que submete a vontade humana na interpretação e construção da história contraria o pensamento benjaminiano de desconstrução desta história destino, desta história catástrofe, que enquadra o movimento da história da humanidade em uma teleologia.

Necessariamente a interpretação da história se converte assim em profecia, e a reta inteligência do passado depende da perspectiva que do futuro se tenha, pois nele alcançam seu fim as significações precedentes ${ }^{4}$

Como bem enfatiza Benjamin, podemos imaginar uma contrapartida filosófica do mecanismo apresentado alegoricamente na primeira de suas teses sobre a filosofia da história (Geschichtsphilosophische Thesen).

Nessa primeira tese, Benjamin relata a história de um autômato construído de tal modo que podia prever os acontecimentos da história e responder a cada lance de um historiador, que é representado pelo jogador que lança leituras, teses e explicações sobre o devir histórico, em disputa com outros interlocutores.

O tabuleiro de xadrez representa o palco da história efetivado no discurso historiográfico que está vinculado ao racionalismo teleológico historicista (grande

3 NEVES, F. Ramos. A História em Fragmentos: Uma leitura das Teses sobre filosofia da história de Walter Benjamin. Dissertação de Mestrado - João Pessoa: UFPB, 2001. p. 31

4 LÖWITH, Karl. El Sentido de la História. Madrid: Aguilar, 1956. p. 216 [TN] 
mesa), presente no materialismo marxista, e rigorosamente fechado em sua significação. Desta forma, neste universo fechado da razão instrumental o autômato ganhará sempre em cada contra lance histórico (previsão por dedução dos axiomas da razão histórica pretendida).

O autômato é por assim dizer um fantoche manipulado pelos cordéis do anão escondido, que metaforicamente representa as leis inexoráveis e imanentes da história, amplamente defendidas pelo marxismo. E o sistema de espelhos que criava a ilusão de que a mesa era totalmente visível (calculável), em todos os seus pormenores, representa metaforicamente o método, as categorias e os princípios absolutos da concepção racionalista da história marxista.

O conceito de história de Marx (ou pelo menos, o do marxismo) - uma máquina atrativa que salvará vitoriosa e forçosamente e sem erro, como todas as máquinas, na partida de xadrez dialética da história evidencia ser apenas uma ilusão conjurada por espelhos. ${ }^{5}$

Como podemos observar, a partir desta leitura hermenêutica da tese 1 , constatamos que Benjamin não concorda em seus escritos com os fundamentos marxistas da filosofia da história; visto que, Marx é considerado herdeiro da visão linear e escatológica da história compreendida como o continuum de uma marcha inexorável comandada por "leis naturais". Na concepção marxista o homem faz sua própria história, mas na medida em que descobre o curso inevitável do "vir-a-ser" que já “é”, que já está ontoteleologicamente ${ }^{6}$ predefinido pelas tensões naturais das leis econômicas do mercado, manifestas pelo descompasso entre forças produtivas e relações sociais de produção.

A concepção de história do marxismo aponta para a ideia de uma objetividade na história que, em "última instância" se os homens não decidirem as leis econômicas e materiais, faz, com suas determinidades, a história acontecer como em um impulso mecânico. E abordar a história a partir da objetividade da produção material separada da subjetividade criadora e reveladora da memória, "da cabeça

\footnotetext{
5 FRIEDMAN, George. La filosofía política de la escuela de Frankfurt. México: Fondo de Cultura Económica, 1986. p. 47.[TN]

6 Habermas define a ontoteleologia enquanto conceito do "agir-racional-com-respeito-a fins" préestabelecidos em uma racionalidade histórica. Um exemplo desta ontoteleologização da história é a ideia do comunismo como "etapa final da história." A respeito ver: HABERMAS, Jürgen. Técnica e ciência enquanto 'ideologia'. In: BENJAMIN, Walter; HORKHEIMER, Max; ADORNO, T. W. ; HABERMAS, J. Textos Escolhidos. São Paulo: Abril Cultural, 1980. (Os Pensadores).
} 
dos homens", é transformar a história da humanidade em um movimento idêntico ao da natureza, cujas ações se efetivam através do encadeamento causal e mecânico de fenômenos sem sujeito pensante. A história é compreendida como o "desenrolar de um novelo já existente".

Esta visão determinista da historia presente na filosofia do marxismo, que Benjamin critica em suas Teses..., também evidencia seu apego ao determinismo de um movimento homogêneo sem a diversidade dos agoras apontados por Benjamin.

Quando Marx elege o proletariado enquanto classe "naturalmente" revolucionária e como sujeito imanente da história, cujo objetivo seria o de pintar o cinza de cinza, isto é, realizar uma finalidade já determinada, que independe de sua vontade e do seu conhecimento, há nesta concepção um determinismo que reforça a ideia tradicional do continuum historicista. Continuum este que aponta o socialismo, como consequência histórica inevitável, advindo de um objetivo meta-histórico, como resultado causal de leis mecânicas da história, que em uma marcha linear e homogênea encaminharia a humanidade a um comunismo escatológico. 0 que Benjamin combate em seu pensamento não é a possibilidade de uma nova sociedade futura, como é o desejo das classes revolucionárias na luta pelo fim da opressão, mas, sobretudo em suas Teses fica claro a crítica desconstrutiva a toda ideia de um absolutismo racional determinista na concepção de história.

E em Marx o modo de produção capitalista, com suas relações sociais de produção engendra determinantemente, a partir do progresso material e econômico (avanço das forças produtivas), a forma de pensar e as demais qualidades espirituais. Esta concepção determinista da história, com um profundo veio positivista e economicista coloca Marx no arcabouço filosófico da tradição racionalista, quanto à filosofia da história, que Benjamin enfaticamente critica em suas teses.

Fazer explodir e desconstruir pela crítica filosófica o continuum historicista da racionalidade instrumental da história presente no pensamento da tradição iluminista, implica em também tecer uma crítica desconstrutiva ao determinismo no pensamento de Karl Marx. Este determinismo economicista do marxismo está 
fundamentado em praticamente todas as suas obras e paradigmas, ${ }^{7}$ sobretudo em seu famoso Prefácio à Contribuição à Crítica da Economia Política publicado em 1859. Em tal obra Marx assim define a história:

Na produção social da sua vida, os homens contraem determinadas relações necessárias e independentes da sua vontade, relações de produção que correspondem a uma determinada fase de desenvolvimento das suas forças produtivas materiais... Erigindo desse conjunto de relações de produção toda a superestrutura. ${ }^{8}$

Marx concebia o avanço e a ideia de progresso da sociedade como uma determinação de ordem econômica, advogando um continuum formalmente vinculado à razão histórica, em uma teleologia inexorável. Conforme as próprias palavras de Marx:

Nenhuma formação social desaparece antes que se desenvolvam todas as forças produtivas que ela contém, e jamais aparecem relações de produção novas e mais altas antes de amadurecerem no seio da própria sociedade antiga as condições para sua existência. ${ }^{9}$

O marxismo ao privilegiar o fator econômico como lei e força motriz da História se identifica com o ideal de razão instrumental absoluta do progresso iluminista da História. Neste sentido, "Marx está inserido na noção iluminista do progresso." ${ }^{10} \mathrm{E}$ foi esta inserção que motivou a ruptura não apenas do Benjamin, mas também da teoria crítica da Escola de Frankfurt, com o marxismo, que, no dizer de Martin Jay, " não apenas deixou para trás os vestígios de uma teoria marxista ortodoxa da ideologia, também implicitamente incluiu Marx na tradição do iluminismo."11

Nesta concepção a História racional é compreendida enquanto o desdobramento inevitável de fases e momentos lógicos na vida da humanidade, cujo princípio de causalidade teleológica vincula-se à ideia de leis naturais imanentes ao próprio fenômeno histórico, que tudo determina desde um passado único e determinante ao futuro escatológico. "Os supostos do Materialismo Histórico sobre a relação

7 Realizo estudo aprofundado sobre a crise paradigmática do pensamento de Karl Marx, e em consequência do marxismo ortodoxo, em minha monografia de graduação, na qual investigo a vida e obra do corifeu do marxismo, apontando as estruturas paradigmáticas de sua crise em suas dimensões ontológicas, gnosiológicas e axiológicas. Ver com mais detalhes em: NEVES, F. Ramos. Marxismo: impotência no pasto da finitude. Monografia de graduação. Natal: DEFIL/ UFRN, 1991.

8 MARX, Karl. Prefácio à contribuição à crítica da economia política. In: MARX, Karl; ENGELS, Friedrich. Obras Escolhidas 1. São Paulo: Alfa-omega, s/d. p. 301

9 MARX, Karl. Op. Cit. p. 302.

10 MATOS, Olgária C. F. Os Arcanos do Inteiramente Outro: A escola de Frankfurt, a melancolia e a revolução. São Paulo: Brasiliense, 1989. p. 67

11 JAY, Martin. La imaginacion dialectica. Madrid: Taurus, 1974. p. 418. [TN] 
dialética entre forças produtivas e relações de produção haviam se transformado em enunciados pseudonormativos sobre uma teleologia objetiva da história."12

Desta forma, em Marx, o "fazer a história" assume o caráter de um processo com uma "legalidade" interna - como um "logos" - que admite "leis" e determinidades. A práxis em Marx encontra-se então em uma relação de cumplicidade com o logos da história, submetendo esta ao domínio imperioso de uma racionalidade instrumental (Zweckrationalität).

Portanto, segundo Hannah Arendt, parece absurdo afirmar que o pensamento benjaminiano "algum dia tenha se preocupado com um processo coerente, dialeticamente sensato, racionalmente explicável," 13 presente nas elaborações teóricas do marxismo.

Para Benjamin a História não pode ser pensada segundo o esquema determinista, porque ela reside no domínio da criação desejante de situações históricas, está repleta de ressignificações e reproduz um ambiente hiper complexo de desconstruções e alegorias. Na qual cada fato não representa um significado em si, mas um significante constantemente problematizado e permanentemente ressignificado. Inclusive o próprio marxismo, na pretensão de uma ciência da objetividade, "impõe aos fatos a racionalidade que deles parece extrair". ${ }^{14}$ Neste sentido o comunismo não é visto enquanto um ideal a ser atingido por deliberação e escolha livre e interna dos sujeitos históricos, mas como consequência "real", não como produto da liberdade, mas como resultado necessário. Isto é, o comunismo na concepção marxista é compreendido como desdobramento e encadeamento causal de fatos, determinados pelo passado, que conduzem a história em um continuum em direção ao progresso teleológico, como bem afirmam Marx e Engels abaixo:

O comunismo não é para nós um estado que deve ser estabelecido, um ideal para o qual a realidade terá que se dirigir. Denominamos comunismo o movimento real que supera o estado de coisas atual. As

12 HABERMAS, Jürgen. Teoría de la acción comunicativa II: crítica de la razón funcionalista. Madrid: Taurus, 1988. pp. 540-541. [TN]

13 ARENDT, Hannah. Walter Benjamin. In. Companhia das Letras, 1987. p. 143. Homens em Tempos Sombrios. São Paulo:

14 CASTORIADIS, Cornelius. A instituição imaginária da sociedade. 3.ed. Rio: Paz e Terra, 1982. p. 68 
condições desse movimento resultam de pressupostos atualmente existentes. ${ }^{15}$

A concepção marxista da história, que se originou no período revolucionário anterior a 1850 como parte integrante da "ação subjetiva" da classe revolucionária, adotada por grandes parcelas do movimento socialista, terminou por evidenciar-se enquanto uma teoria contemplativa do devir humano na história. A teoria marxista, segundo Korsch, se desenvolveu "até converter-se, cada vez mais, em uma teoria contemplativa e meramente abstrata acerca do 'decurso objetivo' da evolução social, determinado por leis exteriores."16

Em nome da ciência materialista da história, e em respeito à objetividade histórica, segundo Castoriadis, "a filosofia da história marxista é, em primeiro lugar, e sobretudo, um racionalismo objetivista" ${ }^{17}$. Devido a esta compreensão sobre devir da história o marxismo hegemônico no início do século XX levou o movimento revolucionário à passividade no desenrolar político da história. Acreditavam que a lógica cega das leis e fenômenos da economia se desdobraria sistematicamente até a realização de uma etapa necessária no devir histórico. Segundo os maiores críticos do marxismo, esta orientação contribuiu para o estancamento das forças revolucionárias em luta o que evidenciou claros indícios de conservadorismo, principalmente no campo de suas categorias teórico-filosóficas.

Enquanto que todo materialismo começa ou termina por degradar a autonomia, exatamente como o idealismo teológico e o positivismo. Todo monismo materialista é inerentemente conservador, porque requer a adequação do 'sujeito' a um destino predeterminado."18

Desta forma, 0 marxismo representa em Benjamin um ponto de vista comprometido com a aceitação de uma certa continuidade histórica. E esta continuidade, como afirma Leandro Konder a seguir:

Era uma continuidade relida à luz dos critérios indicados por Marx e interpretados pelos marxistas, mas era continuidade e esta continuidade era inaceitável. Era a ideia de que o desenvolvimento das forças

MARX, Karl; ENGELS, F. A ideologia alemã. 8.ed. São Paulo: Hucitec, 1991. p. 52

16 KORSCH, Karl. A crise do marxismo. Teoria \& Política São Paulo: Brasil Debates, n. 12 out. 1989. p. 120

17 CASTORIADIS, Cornelius. Op. Cit. p. 55.

18 LEVY, Nelson. Ideologização do Mito do "Reino da Liberdade" na Filosofia da História. Teoria \& Política. São Paulo: Brasil Debates, n. 13, fev. 1990. p. 17. 
produtivas desencadearia uma crise nas relações de produção e forçaria a criação de uma sociedade nova. Isso, para ele [Benjamin], era inteiramente inadmissível; essa ideia era inaceitável. ${ }^{19}$

Segundo Korsch, um dos pontos particularmente críticos do marxismo reside na "aceitação incondicionada da situação avançada inglesa como modelo de desenvolvimento futuro para todos os países e condição objetiva preliminar para a passagem ao socialismo."20 Esta postura mecanicista do marxismo, que concebe história como um nexo causal de leis necessárias e universais, conduzindo determinantemente a humanidade em um progresso teleológico rumo ao comunismo, como fim da história, reflete a enfermidade racionalista do iluminismo triunfante. E podemos verificar que o rumo dos acontecimentos contemporâneos nega e frustra tais ilusões mecanicistas. Entretanto, "na medida que o marxismo havia se ossificado em um sistema que assegurava possuir a chave da verdade, também havia sucumbido vítima da mesma enfermidade." 21

Ainda segundo Korsch, esta postura do marxismo tem sérias e desastrosas consequências políticas. Além da "sobre estimação do Estado como instrumento determinante da revolução social" 22 e da orientação de uma Filosofia da História que identificava a mística economicista e positivista do desenvolvimento da economia capitalista com a revolução social da classe trabalhadora, o marxismo também errou ao desenvolver uma teoria da revolução comunista seguindo etapas necessárias em um continuum que se desdobra "em duas fases e desenvolvida em parte contra Blanqui, em parte contra Bakunin."23

Concordamos que Marx analisou melhor que ninguém um determinante e grave perigo para a humanidade em geral: a iniquidade da exploração do homem pelo próprio homem e, em um nível social, econômico e cultural a exploração do trabalho e dos oprimidos em geral pelo capital e pelos dominantes opressores. Para um diagnóstico acerca deste tipo específico de perigo e das teorias e práticas que o veiculam, a obra de Marx continua indispensável enquanto contribuição na

19 KONDER, Leandro. Filosofia da história em Walter Benjamin. Dossiê Walter Benjamin. São Paulo: Revista da USP, n. 15, set./out./nov. 1992. p. 36.

20 KORSCH, Karl. Dez teses sobre o marxismo hoje. Teoria \& Política. São Paulo: n. 13, fev. 1990. p. 122.

21 JAY, Martin. Op. Cit. p. 91[TN]

22 KORSCH, Karl. Op. Cit. p. 122.

23 Idem. p. 123. 
compreensão aos processos políticos de exploração e opressão social na história da humanidade. Também é muito importante em Marx o ímpeto e desejos revolucionários na luta por uma sociedade justa de novo tipo. Desta forma, é evidente que a indignação que move as forças revolucionárias da atualidade deve muito ao ideal político de liberdade histórica marxista, contra as forças repressoras da sociedade. E Benjamin tem isto muito claro, inclusive propõe um resgate de aspectos importantes na obra de Marx, mas com uma apropriação crítico-desconstrutiva. Por isto Benjamin escreveu a Adorno que era necessário "não aplicar o marxismo ao pé da letra, senão trabalhar com ele, e isso significa, para todos nós, lutar com ele."24

Desta forma, Benjamin não pode ser considerado um marxista, pois realiza um embate teórico-filosófico a muitos dos seus princípios constitutivos. No entanto, por considerar a contribuição marxista, no campo do ideal revolucionário de transformação da sociedade injusta e iníqua do capitalismo, mas ao superá-lo criticamente, sobretudo na desconstrução filosófica de sua concepção de história, podemos considerar o Benjamin um pós-marxista. Um pós-marxista que resgata de Marx o ímpeto revolucionário por uma nova sociedade que suprima o atual estado de coisas, mas pensa contra e além de Marx na construção histórica deste caminho transformador.

Na compreensão do pensamento benjaminiano percebemos que não é possível pensar com atualidade seguindo a concepção de história do marxismo. Isto porque, a periculosidade do marxismo consiste na fé incondicional do mesmo ao ideal de progresso em si da humanidade, e na aceitação religiosa de um escatológico devir da história. Podemos citar o fenômeno do socialismo real no leste europeu, como variante do marxismo, em sua concepção determinista da história, que comprometeu bastante os ideais de liberdade, possibilitando "um poderoso instrumento político-ideológico de legitimação às tendências totalitárias e antihumanistas que se tornaram nítidas a partir do stalinismo."25 Segundo Loparic, Horkheimer foi uma testemunha mais recente e importante sobre os perigos do

24 BENJAMIN, Walter. Apud. BUCK-MORSS, Susan. Origen de la Dialética Negativa. Cerro del Agua: Siglo Veintiuno Ed., 1981. Nota 226, p. 67. [TN]

25 ROLIM, Marcos. Crítica a um marxismo fora do tempo. Teoria \& Política. São Paulo: Brasil Debates, n. 15, dez. 1990. p. 128. 
marxismo quanto à filosofia da História, como podemos observar na citação abaixo:

Já durante a Segunda Guerra Mundial, Horkheimer iniciou em colaboração com Adorno, a busca por um tipo de crítica à sociedade e à ideologia que, além de prática, evitasse ao mesmo tempo dois tipos de perigo: a fé iluminista no progresso e messianismo concreto, exemplificado pelo marxismo e, no passado, pela religião. ${ }^{26}$

Benjamin afirmava que o maior obstáculo para a consciência revolucionária residia na aceitação da crença da história como progresso. E esta aceitação resultou no pacto nazi-soviético, elaborado a partir da orientação do Capital de Marx, que advertia ser o capitalismo uma etapa necessária na marcha histórica rumo ao socialismo. Por isto, "a realização do pacto de não agressão nazi-soviético desiludiu profundamente a Benjamin." 27 E, de acordo com Susan Buck-Morss, Marx compartilha da concepção historicista da história como progresso linear e inevitável no interior de uma teleologia. Marx, afirma Susan,

com certeza compartilha a crença burguesa no progresso, e há muita
coisa nos últimos escritos de Marx que justifica a interpretação de Engels
da dialética como lei natural do desenvolvimento histórico, assim como a
compreensão teleológica da história em Lukács, com sua aceitação da
dominação sobre a natureza. ${ }^{28}$ Para o marxismo a história determinava-se por uma objetividade triunfante no interior de uma teleologia, subordinando a subjetividade criadora do inteiramente novo. Segundo Friedman, estudioso da Escola de Frankfurt, Marx tentava "resolver o conflito da história através do comunismo entendido como resultado necessariamente estatuído para o homem radicalmente determinado." 29

Como os fatos comprovam, sob orientação do Capital, principal obra de Karl Marx, a esquerda marxista se filiou a uma ideia de história teleológica em todos os seus aspectos. Esta concepção arrastou quase que todos os militantes de esquerda para um conformismo socialdemocrata diante da história. E como o próprio Benjamin anuncia em suas teses de 40:

26 LOPARIC, Zeljko. A periculosidade do marxismo. In: periculosidade da filosofia. Campinas: Papirus, 1990. p. 111.

27 BUCK-MORSS, Susan. Op. Cit. pp. 300-301. [TN]

28 Idem. p. 137.

29 FRIEDMAN, George. La filosofía política de la escuela de Frankfurt. México: Fondo de Cultura Económica, 1986. p. 39 
O conformismo, que sempre esteve em seu elemento na socialdemocracia, não condiciona apenas suas táticas políticas, mas também suas ideias econômicas... Nada mais corruptor para a classe operária alemã que a opinião de que ela nadava com a corrente. ${ }^{30}$

Por fim, com a leitura das Teses..., constatamos que a influência de Marx sobre a Escola de Frankfurt, e particularmente sobre Benjamin, no que diz respeito à história, é praticamente nula. Marx considerou a história como uma marcha mecanicamente linear, uniforme e inevitável, que foi o que mais os frankfurtianos criticaram na denúncia dos perigos da razão instrumental. Desta forma, Benjamin e os demais pensadores da Teoria Crítica consideraram Marx como determinista histórico. "Por isso, ao criticar a noção de necessidade histórica, a Escola de Frankfurt advertiu que rompia com Marx." 31

\section{Referências bibliográficas}

ARENDT, Hannah. Walter Benjamin. In. Homens em Tempos Sombrios. São Paulo: Companhia das Letras, 1987.

BENJAMIN, Walter. Teses Sobre o Conceito da História. in. Magia e Técnica, Arte e Política. 2.ed. São Paulo: Brasiliense, 1986. (Obras Escolhidas, v. 1)

BUCK-MORSS, Susan. Origen de la Dialética Negativa. Cerro del Agua: Siglo Veintiuno Ed., 1981.

CASTORIADIS, Cornelius. A instituição imaginária da sociedade. 3.ed. Rio: Paz e Terra, 1982.

FRIEDMAN, George. La filosofía política de la escuela de Frankfurt. México: Fondo de Cultura Económica, 1986.

HABERMAS, Jürgen. Teoría de la acción comunicativa II: crítica de la razón funcionalista. Madrid: Taurus, 1988.

HABERMAS, Jürgen. Técnica e ciência enquanto 'ideologia'. In: BENJAMIN, Walter; HORKHEIMER, Max; ADORNO, T. W. ; HABERMAS, J. Textos Escolhidos. São Paulo: Abril Cultural, 1980. (Os Pensadores).

JAY, Martin. La imaginacion dialectica. Madrid: Taurus, 1974

KONDER, Leandro. Filosofia da história em Walter Benjamin. Dossiê Walter Benjamin. São Paulo: Revista da USP, n. 15, set./out./nov. 1992.

\footnotetext{
30 BENJAMIN, Walter. Teses... tese 11, p. 227.
}

31 FRIEDMAN, George. Op. Cit. p. 46.[TN] 
KORSCH, Karl. A crise do marxismo. Teoria \& Política São Paulo: Brasil Debates, n. 12 out. 1989.

. Dez teses sobre o marxismo hoje. Teoria \& Política. São Paulo: n. 13, fev. 1990.

LEVY, Nelson. Ideologização do Mito do "Reino da Liberdade" na Filosofia da História. Teoria \& Política. São Paulo: Brasil Debates, n. 13, fev. 1990.

LOPARIC, Zeljko. A periculosidade do marxismo. In: Heidegger Réu: Um ensaio sobre a periculosidade da filosofia. Campinas: Papirus, 1990.

LÖWITH, Karl. El Sentido de la História. Madrid: Aguilar, 1956.

MARX, Karl; ENGELS, Friedrich. A ideologia alemã. 8.ed. São Paulo: Hucitec, 1991.

MARX, Karl; ENGELS, Friedrich. Obras Escolhidas 1. São Paulo: Alfa-omega, s/d.

MARX, Karl. Prefácio à contribuição à crítica da economia política. In: MARX, Karl; ENGELS, Friedrich. Obras Escolhidas 1. São Paulo: Alfa-omega, s/d.

MATOS, Olgária C. F. Os Arcanos do Inteiramente Outro: A escola de Frankfurt, a melancolia e a revolução. São Paulo: Brasiliense, 1989.

NEVES, F. Ramos. A História em Fragmentos: Uma leitura das Teses sobre filosofia da história de Walter Benjamin. Dissertação de Mestrado - João Pessoa: UFPB, 2001. 200p.

. Marxismo: impotência no pasto da finitude. Monografia de graduação. Natal: DEFIL/ UFRN, 1991.

ROLIM, Marcos. Crítica a um marxismo fora do tempo. Teoria \& Política. São Paulo: Brasil Debates, n. 15, dez. 1990. 